Discussion

Papers

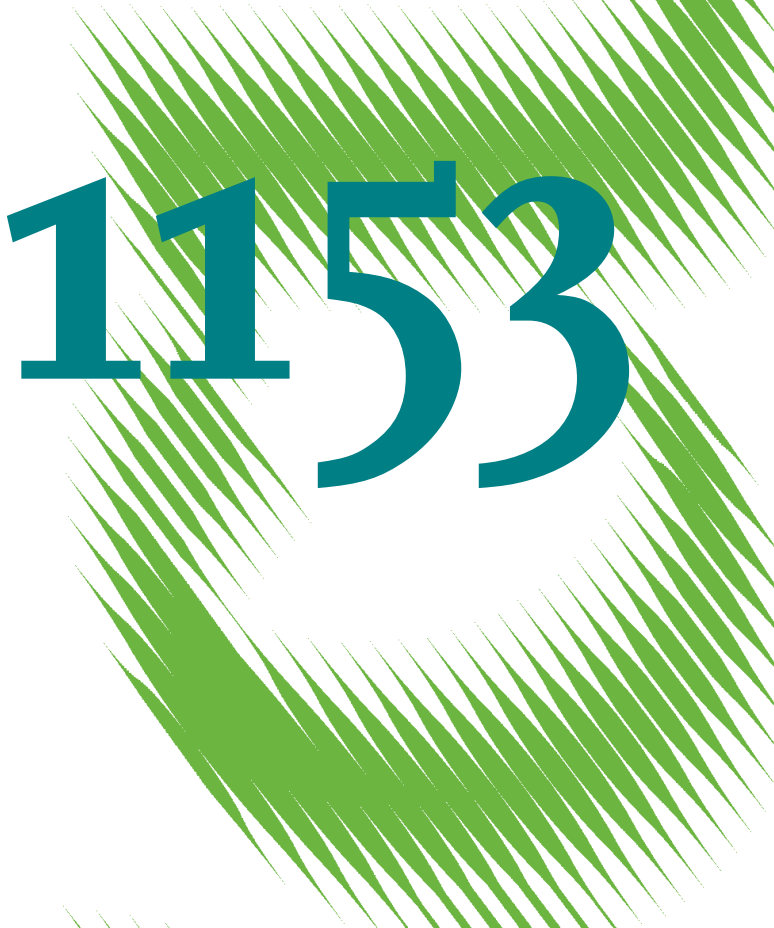

Using Personal Car Register for

Measuring Economic Inequality in Countries with a Large Share of Shadow Economy

Evidence for Latvia 
Opinions expressed in this paper are those of the author(s) and do not necessarily reflect views of the institute.

IMPRESSUM

(C) DIW Berlin, 2011

DIW Berlin

German Institute for Economic Research

Mohrenstr. 58

10117 Berlin

Tel. $+49(30) 89789-0$

Fax +49 (30) $89789-200$

http://www.diw.de

ISSN print edition $1433-0210$

ISSN electronic edition 1619-4535

Papers can be downloaded free of charge from the DIW Berlin website:

http://www.diw.de/discussionpapers

Discussion Papers of DIW Berlin are indexed in RePEc and SSRN:

http://ideas.repec.org/s/diw/diwwpp.html

http://www.ssrn.com/link/DIW-Berlin-German-Inst-Econ-Res.html 


\title{
Using Personal Car Register for Measuring Economic Inequality in Countries with a Large Share of Shadow Economy: Evidence for Latvia*
}

\author{
Vyacheslav Dombrovsky \\ SSE RIGA \& BICEPS \\ Strelnieku str. $4 a$ \\ LV-1010 Riga \\ Latvia \\ slava@biceps.org
}

\author{
Konstantin A. Kholodilin \\ DIW Berlin \\ Mohrenstraße 58 \\ 10117 Berlin \\ Germany \\ kkholodilin@diw.de
}

\author{
Boriss Siliverstovs** \\ ETH Zurich \\ KOF Swiss Economic Institute \\ Weinbergstraße 35 \\ 8092 Zurich, Switzerland \\ boriss.siliverstovs@kof.ethz.ch
}

September 3, 2011

\begin{abstract}
We suggest to use information from the state register of personal cars as an alternative indicator of economic inequality in countries with a large share of shadow economy. We illustrate our approach using the Latvian pool of personal cars. Our main finding is that the extent of household economic inequality in Latvia is much larger than officially assumed. The latest officially available estimate of the Gini coefficient is 0.36 for 2005 , which is much lower than 0.55 for 2009 reported in our paper.
\end{abstract}

Keywords: Economic inequality, cars, social signaling, Gini index, Latvia

JEL code: D31, E26, Z13

\footnotetext{
${ }^{*}$ The first version of the paper was presented at the BICEPS seminar in Riga (Latvia) in May 2010. The paper also benefited from comments of the participants at the conference 'The Shadow Economy, Tax Evasion and Money Laundering' in Münster (Germany) and the KOF Brown Bag seminar in Zurich (Switzerland).

${ }^{* *}$ The corresponding author.
} 



\section{Introduction}

Economic inequality of the households is an important characteristic of the welfare of a country. Societies experiencing too high inequality might be subject to increased levels of criminality, drug and alcohol consumption as well as political instability. Moreover, excessive inequality can have detrimental consequences for economic growth. ${ }^{1}$ Governments pursue various redistributive policies in order to lessen (excessive) inequality among households. However, reliable indicators are needed in order to evaluate the current stance of economic inequality as well as to monitor progress of such policies.

A typical way of how economic inequality is measured is by means of household budget surveys. The data are collected from a limited number of representative households, which are asked to fill in the questionnaires including various questions concerning their expenditure and income. While such a practice of data collection is widespread, there is a number of problematic issues: 1) Only a limited number of households are selected (invited) to participate. 2) The participation is voluntary and verification of supplied information is costly and may not always be possible. 3) The voluntary surveys suffer from the so-called "middle-class bias" (Becker and Hauser, 2003) when households with very high and very low income levels typically are not sufficiently represented.

In countries with a large share of underground economy this type of data collection, that is largely based on voluntary participation, may be more problematic than in developed economies with a good functioning state. In the former countries due to the fact that a lion share of income is derived from unreported economic activity, the respondents may tend to under report their true expenses/earned income in interviews or be less motivated to take part in these surveys. Hence, in those countries one would expect that the reported picture may be more distorted than that in developed countries.

In the current paper we suggest an alternative indicator of economic inequality based on information from a state register of personal cars. In contrast to surveys, where participation is voluntary and verification of provided responses is costly (and if possible at all), the accuracy of information on possessed cars is easy to verify and therefore it is not in the best interests of respondents to provide inaccurate or false statements.

Our suggestion is based on the perception that personal cars because of their intrinsic characteristics are not only means of transportation but also an important device that can be (and widely) used for signaling of social status and hence of economic well-being of their owners. In this respect cars distinguish themselves from other durable goods like washing machines and refrigerators that are kept behind closed doors and therefore are difficult to use to impress other people unless one invites them home. It is reasonable to expect that with a rising level of income/wealth a representative household will be able to afford a better and more expensive car and, more importantly, he/she will do so in order to signal it to his/her surrounding.

The use of personal cars as a signaling device may be even more pronounced in countries of Eastern

\footnotetext{
${ }^{1}$ Thorbecke and Charumilind (2002) provide an extensive review of literature on inequality and its socio-economic impact.
} 
Europe where until the breakdown of the Soviet Union personal cars were one of the most desirable but often unattainable to common people consumer goods. Unsurprisingly that in the aftermath of the fall of the Soviet block, one of the first things that inhabitants did is to satisfy their for a long time suppressed wishes to own a car.

We illustrate the use of information on registered cars for measuring economic inequality using Latvian data as an example. Our choice of Latvia is not purely accidental. Latvia is a small Eastern European country that regained its independence in 1991. Since independence Latvians were very active in acquiring personal cars. In the period from 2000 until 2009 the number of registered cars increased from 299,205 to about 510,000 , peaking to 537,866 in $2007^{2}$. Interestingly, the total population has declined by about $7 \%$ from 2,377,383 (2000 population census) to 2,217,969 (July 2010 estimate) ${ }^{3}$ of people in the same period. This indicates that cars is a popular consumer good that is affordable for a wide range of Latvian people with different incomes and tastes. More importantly, in Latvia there is a substantial share of underground economy. Schneider et al. (2010, p. 23) estimate that in the period 1999-2007 the average size of shadow economy was 29.2 percent of Latvian GDP. The two countries with the smallest shares of shadow economy among considered 21 transition counries are the Slovak and Czech Republics. Ukraine and Georgia are countries with the largest shares, $49.7 \%$ and $65.8 \%$, respectively. In addition, because of devastating effects of the recent financial crisis - it is estimated that during 2008-2009 the Latvian GDP cumulatively declined by about $25 \%$ - and the associated austerity packages implemented by the government (including raise in VAT and other taxes) it is very likely that the share of underground activity in Latvia did not diminish but rather increased in the recent period.

The use of car prices for measuring economic inequality was earlier advocated in a pioneering study of Kholodilin and Siliverstovs (2010). The authors show that in Germany regional measures of economic inequality based on the official data are highly correlated with inequality measures based on regional car prices posted on the Internet. Moreover, it has been also found that there is a rather high correlation between the official estimates of regional income levels and recorded average regional car prices, suggesting that in relatively poor federal (eastern) states people tend to demand smaller and cheaper cars than in more well-off western federal states.

The novelty proposed in this paper is that we utilize the information contained in the state register of personal cars in Latvia for measuring economic inequality among households. For every reported car (make, model, year of production) we approximate its value by prevailing market price. By matching cars with their corresponding prices we are able to construct a proxy for economic well-being of Latvian households that we can use for measuring economic inequality. In contrast to official measures of income inequality our method does not have any significant publication lag and it is very inexpensive. We also show how to take into account inherent uncertainty in pricing of the cars by constructing confidence intervals around our estimates of economic inequality.

\footnotetext{
${ }^{2}$ Data are for cars that passed the compulsory technical examination.

${ }^{3} \mathrm{https}$ ///www.cia.gov/library/publications/the-world-factbook/geos/lg.html
} 


\section{Data}

The data on personal cars registered in Latvia were graciously provided by the Latvian Road Traffic Safety Directorate (CSDD). The car pool comprises those cars that were registered on the 31th December 2009. Only those cars were included that passed the compulsory technical examination. The data are anonimised and highly aggregated. We have only the following information at our disposal: car make, name of a model, year of production, owner type (private or organization), and the corresponding number of cars. Unfortunately, any information either on mileage or engine volume is absent.

In total, 510,959 personal cars were registered on the 31th December 2009 in Latvia. For our estimations we retained only those cars that were built starting from 1980. The reason for such a choice is twofold. First, it is quite difficult to evaluate older cars since there is not much price information available. Second, given their age it is very likely that such cars are not that much used for everyday traveling but perhaps are mainly kept for other reasons. We also removed from our sample military cars like Hummer HMMWVM1151 or VW ILTIS, since it was also quite difficult to find prices for such cars. Fortunately, there were not so many of those. In the end we were left with 508,701 cars. These cars were registered both by private persons as well as legal entities (commercial firms and organizations). In practice, it is quite difficult, however, to separate the use of cars for private rather than for business purposes. Hence our first set of the results is based on all cars. We check the robustness of our results by estimating the level of inequality using cars registered by private persons only.

The data on car prices were downloaded from the popular German Internet site hosting car selling advertisements (www.mobile.de) in May 2010. In total we collected 873,796 unique price quotes. We use this rich source of information in order to determine an approximate value of each car registered in Latvia by matching the following car characteristics (make, model, production year) in the register with the corresponding information posted in this website.

\section{Results}

In this section we present our results. First we describe the results obtained using all cars registered both to persons and organizations, see Table 1 . Then we briefly report the results obtained using a subset of cars registered to persons, see Table 2 .

The bottom line of Table 1 reports that there were 508,701 personal cars registered in Latvia with the earliest year of production 1980 (the stand of 31st December, 2009). Using the website (www.mobile.de) we did not find any price for 12,562 of them which comprises about $2.5 \%$. For the rest of the cars we could find at least one price quotation. For those cars for which we did not find any prices, we had to use the available information in order to find out a reasoble price for them. In order to do this we used car categories specified at http://en.wikipedia.org/wiki/Car_classification. Observe that in our approach we mixed both classifications referred to as American English and British English in this website. From each classification we picked up the most detailed breakdown of cars. For example, in the American English 
classification the "subcompact" class of cars includes "city car" and "supermini" categories of the British English classification, such that in table reporting the estimation results we used these two categories instead of one. In addition, we distinguished between four subcategories of the "sports" cars. The reasons for doing so is that this category of cars is very heterogenous: on the one hand we have a low-prices sports cars like HYUNDAI SCOUPE, on the other hand-rather expensive cars like LAMBORGHINI MURCIÉLAGO.

The left panel of Table 1 provides a breakdown of cars according to the mentioned categories. The largest category of the cars is "compact" followed by "mid-size". Also cars belonging to the "entry lux" and "mid-size lux" categories are quite popular in Latvia. The column "Non-matched" reports a number of cars in each category for which we could not find a single price. In general we were unable to match prices for older cars that are no longer sold in Germany, Soviet-made cars (like UAZ in "mini SUV"), and American cars (like CHEVROLET LUMINA or DODGE INTREPID in "full-size").

Since we only dispose of a very aggregated information on each car, its evaluation is necessary confronted with inherent uncertainty that we have to account for. Fortunately for most cars with known for us characteristics (make-model-year of production) we have more than a single price observation. For example, for VW GOLF produced in 2008 we have 419 registered cars and 4190 corresponding price quotations. We use these multiple price observations in order to approximate this uncertainty. In order to compute a value of Gini coefficient we assign prices to cars by the following two procedures. For the sake of illustration we continue with the example of VW-GOLF-2008. In the first procedure we randomly draw (with replacement) a vector of size 419 from available 4190 prices such that each of 419 registered cars gets assigned its own price. We repeat this procedure for every model in our sample, which in the end gives us a vector of assigned prices of length corresponding to the total number of cars $(508,701)$. Now we can use this vector of assigned prices in order to compute Gini coefficient. In the second procedure we randomly draw only one price from available 4190 prices and assign this price to each of 419 cars. Then we repeat this procedure for every model in our sample and subsequently compute Gini coefficient. We repeat each of the two procedures 100 times. As a result we have a distribution of Gini coefficient values. We report the descriptive statistics of this distribution in Table 1 in columns (4) - (7) and (8)-(11) for the first and second procedures, respectively.

We also use these two procedures in order to assign prices to 12562 cars for which we could not find a single price observation. For those cars without matched prices we assigned a price by exploiting our knowledge about a category to which it belongs and a year of production. According to the first procedure we draw a vector of size corresponding to a number of cars from a set of prices for those cars that were build in the same year and belong to the same class. According to the second procedure we randomly draw a single price from the mentioned set of prices and assign this price to every car with these characteristics.

Estimation results for all car categories are reported in the last row of Table 1. The mean values of the obtained distribution of Gini coefficients computed by these two approaches are practically the same $(0.551$, subject to rounding). However, the standard deviations of the respective distributions differ. In the first procedure the variation is negligible (observed maximal and minimal values of Gini coefficients are 0.552 and 0.550 , and the standard deviation is 0.000), whereas the second approach yields maximal and minimal values of 0.591 and 0.544 , with the standard deviation of 0.007 . A similar conclusion can be reached when 
comparing estimation results for car classes.

In order to check the robustness of our results we replicated these two procedures using cars registered only on physical persons, see Table 2 . The sample size reduces to 428,972 cars, and for 11411 cars we could not find a single price observation. The mean values of the Gini coefficient are 0.534 and 0.533 for the first and second procedures, respectively. These values are very close to those reported for the whole car pool.

The car-based evaluation of income inequality can (and should) be compared to official measures based on household budget surveys. The survey-based measures of Gini coefficients available to us are for years 1988 (0.225, Rauhmane et al., 2010), 1997 (0.338, Fofack and Monga, 2004), 2000 (0.373, Fofack and Monga, 2004), and 2005 (0.360, CIA, 2011). In 1988 Latvia still was a part of the Soviet Union and that explains a rather low value of the Gini coefficient. In post-Soviet period the value of the Gini coefficient somewhat stabilized around 0.35, which is much lower than we reported above in Tables 1 and 2.

In sum, our approach to measuring the economic inequality among Latvian households suggests that it is much more pronounced than officially reported. It is interesting to note that the reported value of the Gini coefficient is practically the same whether we use all the cars registered to both physical persons and legal entities or only those cars registered to physical persons. The main argument for using our approach for measuring inequality in countries with a formidable share of shadow economy is that on the one hand respondents generally are less motivated to disclose their true levels of income/expenses in interviews than in countries with smaller levels of underground activity. On the other hand, it is in their best interests to accurately report to the register of the road police what car do they drive.

However, our approach is based on several assumptions which will be discussed below. We also will speculate on likely consequences for estimated values of the Gini coefficient in case these assumptions are likely to be violated. The first assumption that we made that there is only one car per household. This certainly may true for families with lower income but may be not hold for richer families, where both husband and wife may each have a car to drive. Although we do not have any information on car ownership per household, we can conjecture that if we could account for that this resulted even in higher values of the Gini coefficient.

Our second major assumption is that there is no sample selection bias in car ownership. Although it is not difficult to imagine households that for some reasons choose not to own a car. For example a single pensioner, who struggles to pay his monthly rent, surely cannot afford it. Or, a green-minded well-off family that on purpose decided not to have a car because of environmental concerns and choose to use the public transportation instead. Accounting for those people who cannot afford a car in our approach is equivalent of adding very low prices to those prices that we already have. In doing that we are likely to increase further value of the Gini coefficient. With respect to those people that choose not to own a car because of other than financial reasons, we argue that in Latvia those people are rather exception than the rule: in fact in Latvia, those who can afford a car-buy it. As said above, a car is a common good in Latvia that offers great variety both concerning price and buyers' taste, and it is very helpful for social signaling.

Our third assumption is that there is that the elasticity of expenditure on car with respect to income is positive and close to unity. We also implicitly assume that households with a similar income spent a similar 
share of their budget on car. Again it is difficult to judge to what extent it holds in Latvia, as those with less income may be tempted to spend a larger share of their income on a car in order to appear better off than actually he is. At the same time, very rich households may spend a smaller share of their income on their cars than does an average household. For example, instead of buying a LAMBORGHINI MURCIÉLAGO they may settle for a PORSCHE PANAMERA. Accounting for tendency of relatively poor households to over-spent and of better-off households to under-spent on cars is likely further to increase value of Gini coefficient in our approach.

In our car evaluation exercise we deployed German prices. In doing so we implicitly assume that the price structure at the German car market is similar to that in Latvia. To the certain extent this seems to be not far away from the truth as most of the (second-hand) cars are imported to the Latvian market from Germany. An advantage of using the German prices is that it helps us directly match prices to a corresponding car for more than $97 \%$ of the registered cars. As an alternative we could have used the local prices in order to determine an approximate price for a car. But compared to almost 900,000 price quations available in Germany, there is only about 4,500 prices that we could find at the Latvian website (www.ss.lv) with car sale announcements. This number is substantially smaller implying that for a large portion of cars it is not possible to directly find the corresponding prices. Moreover, German prices are also more heterogeneous for a given set of characteresitcs (make - model-year of production) that we have at our disposal, allowing us better to account for evaluation uncertainty of cars with these characteristics.

Finally, we acknowledge that the prices placed on the web are not the end selling but offer prices. The former prices can naturally deviate from the latter but we do not have any information by how much.

\section{Conclusions}

In this paper we suggest an alternative method of measuring the extent of economic inequality between households. Rather than directly asking (a subset of) households regarding their incomes and expenditures, we suggest to infer indirectly their incomes by assessing an approximate value of their cars. We expect that our method delivers more precise results especially in countries where a lion share of income is derived from underground activity. In those countries we expect that the respondents are less likely to provide true answers during the interviews or are less motivated to participate in the budget surveys at all. As a result, inequality measures based on household budget surveys are likely to be downwards biased. In contrast, our approach is based on accurate and easy verifiable information reported by the respondents to the road police register about the cars they own.

As an illustration of our approach we use Latvian data on car ownership. For each car model we assign a corresponding price using information from the Internet advertisements placed on the popular German website with car advertisements. We compute the Gini coefficient based on the assigned car prices and find out that our estimates of Gini coefficient are much higher than those reported on the basis of household budget surveys. The latest officially available estimate of Gini coefficient is 0.36 for 2005, which is much lower than 0.55 reported in our paper. 


\section{References}

Becker, I. and R. Hauser (2003). Anatomie der Einkommenverteilung. Berlin.

CIA (2011). The world factbook. online: https://www.cia.gov/library/publications/the-worldfactbook/geos/lg.html.

Fofack, H. and C. Monga (2004). Dynamics of income inequality and welfare in Latvia in the late 1990. World Bank Policy Research Working Paper 3336, University Library of Munich, Germany.

Kholodilin, K. A. and B. Siliverstovs (2010). Measuring regional inequality by internet car price advertisements: Evidence for Germany. KOF Working papers 10-261, KOF Swiss Economic Institute, ETH Zurich.

Rauhmane, S., I. Palma, and I. Sloka (2010). Intra-industrial and intra-regional wage differentials in Latvia. Working pape, EuroFaculty.

Schneider, F., A. Buehn, and C. E. Montenegro (2010). Shadow economies all over the world : New estimates for 162 countries from 1999 to 2007. Policy Research Working Paper Series 5356, The World Bank.

Thorbecke, E. and C. Charumilind (2002). Economic inequality and its socioeconomic impact. World Development 30(9), 1477-1495. 
Table 1: Results obtained for all cars

\begin{tabular}{|c|c|c|c|c|c|c|c|c|c|c|c|}
\hline & \multicolumn{2}{|c|}{ Number } & \multirow[b]{2}{*}{$\begin{array}{c}(3) \\
\text { Non-matched, } \%\end{array}$} & \multicolumn{4}{|c|}{ Gini coefficient (I) } & \multicolumn{4}{|c|}{ Gini coefficient (II) } \\
\hline & $\begin{array}{r}(1) \\
\text { Total }\end{array}$ & $\begin{array}{r}(2) \\
\text { Non-matched }\end{array}$ & & $\begin{array}{l}(4) \\
\text { mean }\end{array}$ & $\begin{array}{c}\text { (5) } \\
\text { st.dev }\end{array}$ & $\begin{array}{l}(6) \\
\max \end{array}$ & $\begin{array}{l}(7) \\
\min \end{array}$ & $\begin{array}{l}(8) \\
\text { mean }\end{array}$ & $\begin{array}{c}\text { (9) } \\
\text { st.dev }\end{array}$ & $\begin{array}{l}(10) \\
\max \end{array}$ & $\begin{array}{l}(11) \\
\min \end{array}$ \\
\hline Microcar & 144 & 0 & 0.0 & 0.193 & 0.010 & 0.220 & 0.170 & 0.186 & 0.028 & 0.261 & 0.136 \\
\hline City car & 4207 & 177 & 4.2 & 0.401 & 0.002 & 0.407 & 0.396 & 0.396 & 0.015 & 0.440 & 0.364 \\
\hline Supermini & 23044 & 375 & 1.6 & 0.381 & 0.001 & 0.383 & 0.379 & 0.382 & 0.007 & 0.401 & 0.368 \\
\hline Compact & 127621 & 5761 & 4.5 & 0.518 & 0.000 & 0.519 & 0.516 & 0.518 & 0.008 & 0.551 & 0.500 \\
\hline Entry lux & 72395 & 175 & 0.2 & 0.528 & 0.001 & 0.530 & 0.527 & 0.528 & 0.014 & 0.562 & 0.492 \\
\hline Mid-size & 100068 & 910 & 0.9 & 0.561 & 0.001 & 0.563 & 0.559 & 0.560 & 0.010 & 0.594 & 0.539 \\
\hline Mid-size lux & 65507 & 636 & 1.0 & 0.530 & 0.002 & 0.536 & 0.524 & 0.532 & 0.033 & 0.733 & 0.508 \\
\hline Full-size lux & 7515 & 66 & 0.9 & 0.581 & 0.002 & 0.587 & 0.573 & 0.580 & 0.007 & 0.599 & 0.559 \\
\hline Sports (low) & 701 & 26 & 3.7 & 0.394 & 0.004 & 0.408 & 0.382 & 0.390 & 0.016 & 0.427 & 0.351 \\
\hline Sports (mid) & 207 & 4 & 1.9 & 0.301 & 0.008 & 0.325 & 0.284 & 0.302 & 0.015 & 0.344 & 0.263 \\
\hline Sports (high) & 72 & 5 & 6.9 & 0.180 & 0.010 & 0.207 & 0.149 & 0.173 & 0.016 & 0.218 & 0.144 \\
\hline Sports (lux) & 138 & 3 & 2.2 & 0.412 & 0.019 & 0.492 & 0.382 & 0.408 & 0.018 & 0.453 & 0.370 \\
\hline Super & 6 & 2 & 33.3 & 0.312 & 0.081 & 0.477 & 0.121 & 0.237 & 0.045 & 0.346 & 0.137 \\
\hline Ponycar & 124 & 3 & 2.4 & 0.361 & 0.017 & 0.400 & 0.312 & 0.357 & 0.030 & 0.443 & 0.298 \\
\hline Grand tourer & 424 & 17 & 4.0 & 0.472 & 0.004 & 0.482 & 0.465 & 0.472 & 0.007 & 0.490 & 0.456 \\
\hline Convertible & 3804 & 5 & 0.1 & 0.410 & 0.003 & 0.415 & 0.403 & 0.404 & 0.022 & 0.451 & 0.329 \\
\hline Roadster & 501 & 3 & 0.6 & 0.344 & 0.006 & 0.359 & 0.330 & 0.342 & 0.012 & 0.371 & 0.315 \\
\hline Mini MPV & 4039 & 252 & 6.2 & 0.256 & 0.002 & 0.260 & 0.251 & 0.254 & 0.009 & 0.279 & 0.233 \\
\hline Compact MPV & 11848 & 183 & 1.5 & 0.342 & 0.001 & 0.345 & 0.340 & 0.340 & 0.008 & 0.355 & 0.319 \\
\hline Large MPV & 22124 & 2072 & 9.4 & 0.448 & 0.001 & 0.450 & 0.445 & 0.447 & 0.008 & 0.474 & 0.429 \\
\hline Full-size van & 3212 & 89 & 2.8 & 0.449 & 0.003 & 0.456 & 0.442 & 0.448 & 0.021 & 0.517 & 0.403 \\
\hline $\mathrm{LCV}$ & 10710 & 85 & 0.8 & 0.457 & 0.002 & 0.461 & 0.452 & 0.455 & 0.011 & 0.490 & 0.428 \\
\hline Mini SUV & 2758 & 395 & 14.3 & 0.399 & 0.003 & 0.406 & 0.390 & 0.397 & 0.012 & 0.434 & 0.360 \\
\hline Compact SUV & 16708 & 237 & 1.4 & 0.322 & 0.001 & 0.324 & 0.319 & 0.321 & 0.005 & 0.339 & 0.309 \\
\hline Coupe SUV & 193 & 0 & 0.0 & 0.270 & 0.008 & 0.285 & 0.245 & 0.267 & 0.024 & 0.336 & 0.209 \\
\hline Mid-size SUV & 15168 & 404 & 2.7 & 0.380 & 0.001 & 0.383 & 0.377 & 0.379 & 0.006 & 0.397 & 0.364 \\
\hline Full-size SUV & 6173 & 116 & 1.9 & 0.337 & 0.002 & 0.342 & 0.332 & 0.335 & 0.015 & 0.373 & 0.302 \\
\hline Mid-size picku & 6 & 4 & 66.7 & 0.256 & 0.068 & 0.441 & 0.127 & 0.259 & 0.056 & 0.463 & 0.126 \\
\hline Full-size pickup & 43 & 0 & 0.0 & 0.313 & 0.033 & 0.383 & 0.224 & 0.305 & 0.035 & 0.383 & 0.196 \\
\hline Super-duty pickup & 2 & 2 & 100.0 & 0.076 & 0.079 & 0.158 & 0.000 & 0.000 & 0.000 & 0.000 & 0.000 \\
\hline All & 508701 & 12562 & 2.5 & 0.551 & 0.000 & 0.552 & 0.550 & 0.551 & 0.007 & 0.591 & 0.544 \\
\hline
\end{tabular}

Notes: in columns (4) - (7) and (8) -(11) we report the descriptive statistics of the distribution of Gini coefficient calculated according to the first and second procedures, see Section 3 for the description. The respective distributions were obtained using 100 random drawings.

Table 2: Results obtained for cars registered on private persons

\begin{tabular}{|c|c|c|c|c|c|c|c|c|c|c|c|}
\hline Class & $\begin{array}{r}(1) \\
\text { Total } \\
\end{array}$ & $\begin{array}{l}\text { Number } \\
\text { Non-matched }\end{array}$ & $\begin{array}{c}(3) \\
\text { Non-matched, \% }\end{array}$ & $\begin{array}{c}(4) \\
\text { mean }\end{array}$ & $\begin{array}{l}(5) \\
\text { Gini coe } \\
\text { st.dev }\end{array}$ & $\begin{array}{l}(6) \\
\text { cient (I) } \\
\max \end{array}$ & $\begin{array}{l}(7) \\
\min \end{array}$ & $\begin{array}{c}(8) \\
\text { mean }\end{array}$ & $\begin{array}{l}\text { (9) } \\
\text { Gini coef } \\
\text { st.dev }\end{array}$ & $\begin{array}{l}(10) \\
\text { cient (II) } \\
\text { max }\end{array}$ & $\begin{array}{l}(11) \\
\min \end{array}$ \\
\hline Supermini & 18293 & 371 & 2.0 & 0.413 & 0.001 & 0.414 & 0.411 & 0.412 & 0.008 & 0.430 & 0.393 \\
\hline Compact & 109860 & 5599 & 5.1 & 0.518 & 0.001 & 0.520 & 0.517 & 0.518 & 0.011 & 0.557 & 0.490 \\
\hline Entry lux & 68508 & 159 & 0.2 & 0.497 & 0.001 & 0.499 & 0.495 & 0.495 & 0.017 & 0.546 & 0.457 \\
\hline Mid-size & 89882 & 865 & 1.0 & 0.533 & 0.001 & 0.536 & 0.530 & 0.533 & 0.014 & 0.569 & 0.501 \\
\hline Sports (low) & 622 & 26 & 4.2 & 0.403 & 0.005 & 0.418 & 0.390 & 0.402 & 0.022 & 0.442 & 0.338 \\
\hline Sports (mid) & 151 & 4 & 2.6 & 0.311 & 0.010 & 0.336 & 0.286 & 0.313 & 0.017 & 0.363 & 0.280 \\
\hline Sports (high) & 41 & 5 & 12.2 & 0.228 & 0.017 & 0.275 & 0.189 & 0.226 & 0.021 & 0.282 & 0.176 \\
\hline Sports (lux) & 79 & 1 & 1.3 & 0.477 & 0.019 & 0.604 & 0.450 & 0.475 & 0.028 & 0.619 & 0.416 \\
\hline Super & 2 & 0 & 0.0 & 0.192 & 0.075 & 0.352 & 0.151 & 0.200 & 0.081 & 0.352 & 0.151 \\
\hline Ponycar & 114 & 3 & 2.6 & 0.355 & 0.017 & 0.404 & 0.311 & 0.350 & 0.035 & 0.433 & 0.264 \\
\hline Grand tourer & 263 & 16 & 6.1 & 0.515 & 0.006 & 0.529 & 0.500 & 0.514 & 0.010 & 0.539 & 0.482 \\
\hline Convertible & 3176 & 4 & 0.1 & 0.371 & 0.003 & 0.376 & 0.366 & 0.366 & 0.022 & 0.409 & 0.311 \\
\hline Roadster & 412 & 3 & 0.7 & 0.331 & 0.007 & 0.347 & 0.314 & 0.328 & 0.015 & 0.380 & 0.299 \\
\hline Mini SUV & 1809 & 308 & 17.0 & 0.392 & 0.005 & 0.404 & 0.383 & 0.389 & 0.016 & 0.438 & 0.352 \\
\hline Compact SUV & 11487 & 147 & 1.3 & 0.350 & 0.001 & 0.353 & 0.348 & 0.350 & 0.007 & 0.368 & 0.333 \\
\hline Coupe SUV & 95 & 0 & 0.0 & 0.304 & 0.011 & 0.334 & 0.279 & 0.294 & 0.027 & 0.378 & 0.234 \\
\hline Mid-size SUV & 9504 & 210 & 2.2 & 0.398 & 0.001 & 0.401 & 0.395 & 0.398 & 0.006 & 0.412 & 0.384 \\
\hline Full-size SUV & 3101 & 80 & 2.6 & 0.382 & 0.003 & 0.388 & 0.376 & 0.381 & 0.017 & 0.425 & 0.349 \\
\hline Mid-size pickup & 3 & 1 & 33.3 & 0.282 & 0.072 & 0.478 & 0.119 & 0.290 & 0.081 & 0.478 & 0.095 \\
\hline Full-size pickup & 29 & 0 & 0.0 & 0.308 & 0.036 & 0.389 & 0.214 & 0.306 & 0.045 & 0.405 & 0.171 \\
\hline All & 428972 & 11411 & 2.7 & 0.534 & 0.000 & 0.535 & 0.533 & 0.533 & 0.005 & 0.551 & 0.522 \\
\hline
\end{tabular}

Notes: see Table 1. 